\title{
Exploring the Career Capital Impact of International Assignments within Distinct Organizational Contexts Noeleen Doherty \\ June 2009
}

AK Welcome to the Talking Paper Series. My name is Andrew Kirchner, I am joined today by Noeleen Doherty. We are talking about a paper that Noeleen wrote with Michael Dickmann entitled 'Exploring the Career Capital Impact of International Assignments within Distinct Organizational Contexts'. It has been published in The British Journal of Management, Volume 19, 2008.

So Noeleen, what do you mean by career capital?

ND Career capital is a concept now that is gaining increasing credibility and usage within the career research field. It is a conceptual framework developed by DeFillippi and Arthur and it basically constitutes three sets of areas. It is around your 'knowing how' - which are the sets of skills, knowledge and abilities which you bring with you to a job; it's around your 'knowing whom' which are the capabilities that are developed through your networks and social contacts; and the third aspect 'knowing why' which basically is around individual motivation, energy and commitment to the work.

AK So how did you do your research?

ND This particular piece of work was conducted as a case study approach within two organisations. Both companies had an established history of international assignment; they had large cadres of individuals who went on assignment and it was a key part of the career development within each organisation.

The case study approach facilitated in depth insights into both the policy, practice and the individual perceptions of the international assignment episode.

AK And what were the findings?

ND For this particular piece of work, we found differential aspects of career capital development within the two organisational contexts. Organisation 1 was in financial services: in that particular setting they had very clear formal policies and practices to help people through the international assignment experience. In contrast, the second company which was in the FMCG sector had a less formal approach; policies and practices were in place, but in their application they were much more informal. 
AK So which worked best for the international assignment?

ND I think they worked differently which is probably the key message of this paper. Within the FMCG context, because there was a high degree of informality, the individual assignees took a lot more responsibility in terms of developing - particularly their own networks. So their 'knowing whom' became very much a concerted focus in terms of their network behaviour and development of networks while they were on international assignments.

The 'knowing whom' has the potential to decrease also. Within the FMCG company there were no explicit policies to support networking, so individuals found that when they came back they had maybe lost a little bit of contact and touch with $\mathrm{HQ}$. And in terms of career capital development that can sometimes have a detrimental effect on progression. Maintaining a network at home base is quite an important issue in terms of regaining career positioning on return. And that can obviously lead to potential challenges to retention. Organisations who are investing a lot of money in developing international assignees usually do it with the intention to maintain and retain that individual on return.

And I think one of the key contributions of this paper is that there are certain points of departure from what is currently stated in the literature; that there is a mutually beneficial situation doing an international assignment for both company and individual. This paper highlights that within different organisational contexts the way things are managed can lead to different behaviours among the individuals and potentially not always positive outcomes for either or both.

AK Noeleen, thank you very much indeed. 